\title{
Global Vulnerability Projection on Storm Surges Due to Tropical Cyclones
}

\section{茨城大学}

\author{
Hisamichi Nobuoka \\ Nobuo Mimura
}

Ibaraki University, JAPAN [nobuoka@mx.ibaraki.ac.jp]

Ibaraki University, JAPAN
Introduction

Coastal zones is one of the severe vulnerability area in the 21st century because of impact of rise in sea level according to global warming and increase in population, especially in mega-deltas. The vulnerability assessment in coastal zone can contribute to not only necessity of mitigation but also adaptation, against the global warming and the population problem. Though Hoozemans et al. (1993), Robert Nichols et at. (1999) and their later works carried out the basic assessments of coastal vulnerability in the world, the (1999) and their later works carried out the basic assessments of coas
storm surges and high-astronomical tides did not hold enough accuracy.

The purpose of this paper is to present the global map of storm surges and that flooding area, which made by the results of numerical simulation of storm surges due to tropical cyclones in last 50 years. Moreover, increase in flooded population by the storm surges is also projected during the 21st century.

\section{Assessment Methodology}

The impact from the sea was the highest storm surge with high astronomical tide and rise in sea level at all of the coasts (Figure 1).

The heights of storm surges were calculated by use of a numerical calculated by use of a numerical long-wave theory. Winds and atmospheric pressure of tropical cyclones on sea surfaces were hindcasted by the empirical equation proposed by Myers(1954).

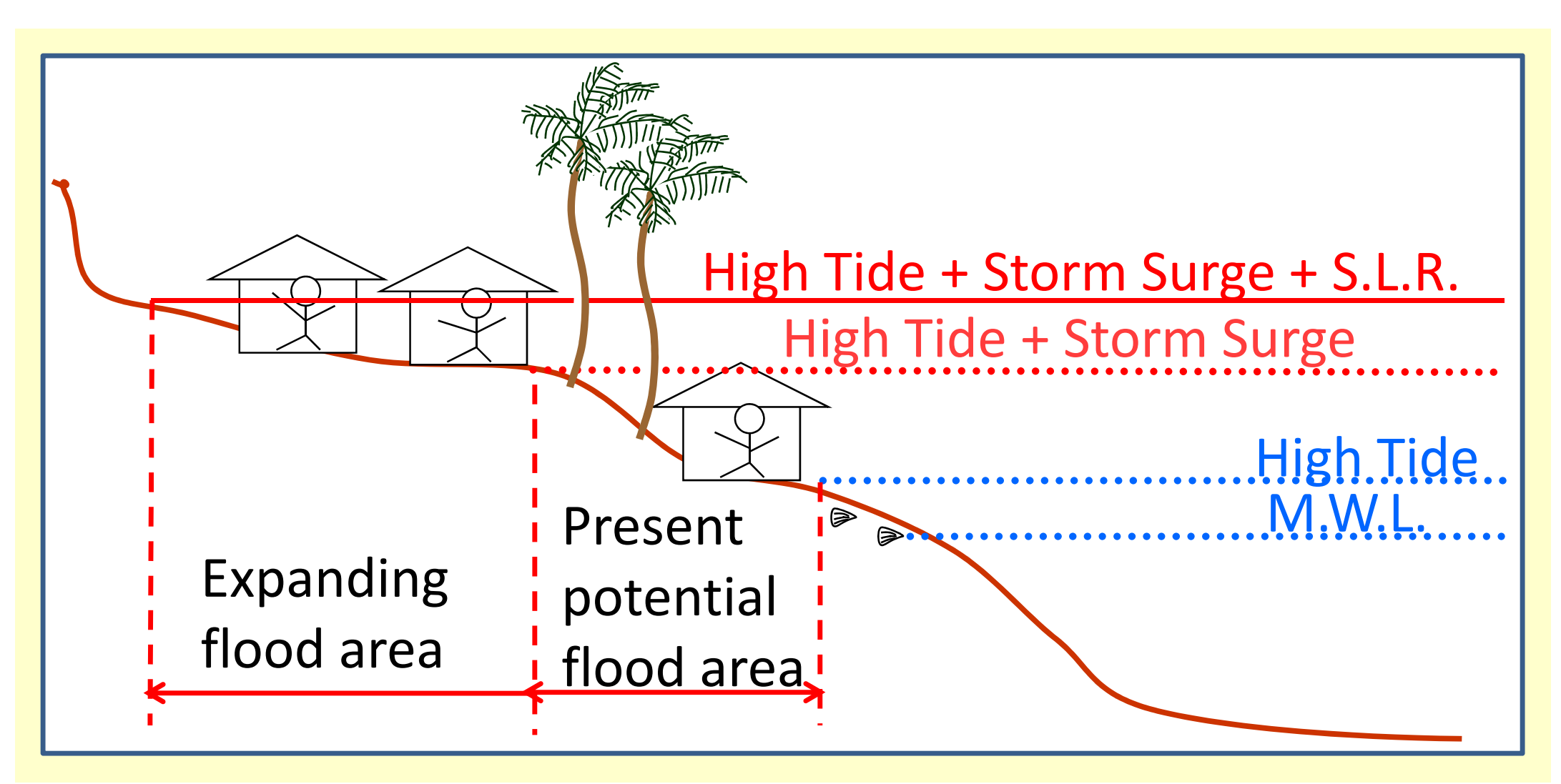

Figure 1. Scheck of Impact and Vulnerability along coasts
The number of tracks of tropical cyclones called 'best track' of tropical cyclones is over 4000 distributed by JAPAN Meteorological Agency of Japan and IBTrACS of NOAA. The spatial grid size and integral timestep of the calculation were 2 arc-minute and 5 minute, respectively. The heights for the assessment were downscaled to 60 arc-seconds.

The flood areas due to the impacts were calculated by a simple method of level comparison between ground elevations and water levels, taking into account a route from each coastal line. The digital elevation model, GTOPO30 of USGS of NASA, served as the base for this ground elevations. As artificial coastal defences were not considered in this analysis, the area where water reached should be called the 'potential flooding area'. Finally, the population in each flooding area was counted. The scenarios of population growth and sea-level rises in the 21st century are according to Special Reports of Emission Scenarios, IPCC(2000).

\section{Main Assessment Results}

Figure 2 is a presented global map of the storm surges due to tropical cyclones. Calculated hot spots of the storm surges are around Gulf of Mexico, Bay of Bengal and East Asia coasts, which is agreement with our experiences.

The projected extension of the flooded area is shown in Figure 3. The base area is $1,770,000 \mathrm{~km}^{2}$ in 2000. The extended area for 2000 to 2100 in the A1B and A2 scenarios becomes about 160,000 and $180,000 \mathrm{~km}^{2}$, respectively. The extended areas in Asia and North America are slightly larger than in other areas. The trend of the extension for 2000 to 2100 over the world is the same as that for the sea-level rise. The increase in the flooded population from storm surge with a sea-level rise is also shown in Figure 3. The increase in population of Asia occupies the major portion of that of the world. Both the impact of sealevel rise and population growth are included in the results of the increase in the affected population. The increase in affected population continues till 2100 in the A2 scenario, which also continues positive population growth. At present, 436 million people in the world are affected by the potential impact of floods; the A2 scenario projected an increase in this number to about 600 million people by 2100 . On the other hand, the increase in affected population is restrained in the A1B and B2 scenarios, in which population growth becomes negative after 2050.

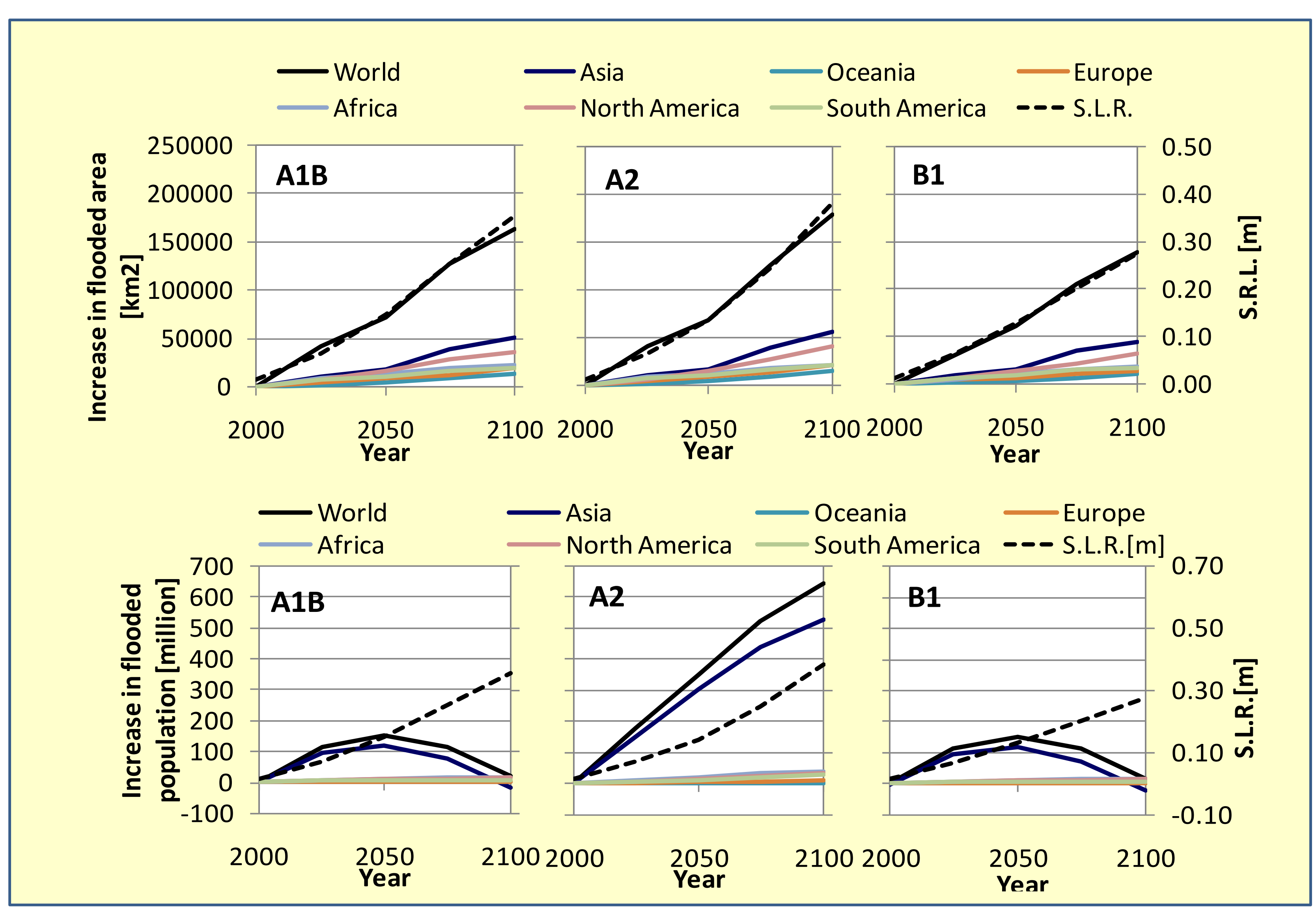

Figure 3. Increase in flooding area (Top figure) and flooded population(Bottom Figure) from 2000 to 2100 (S.L.R. is average of the values of two Japanese GCMs)

Figure 4 shows the relative change in the population increase of flooded areas over the 21st century in A2 SRES scenario as a proportion of the total population of that region, in other words, the relative increase in population in flooded areas. The effects of population growth and sea-level rise on these results are also separated by considering the increase in flooded population. These results indicate that Oceania and Asia are affected in approximately the same proportions. In all scenarios and regions, the impact of the sea-level rise will be significant in the latter half of the 21st century. Up to this point, the increase in population living in potentially flooded areas grows due to natural population growth.

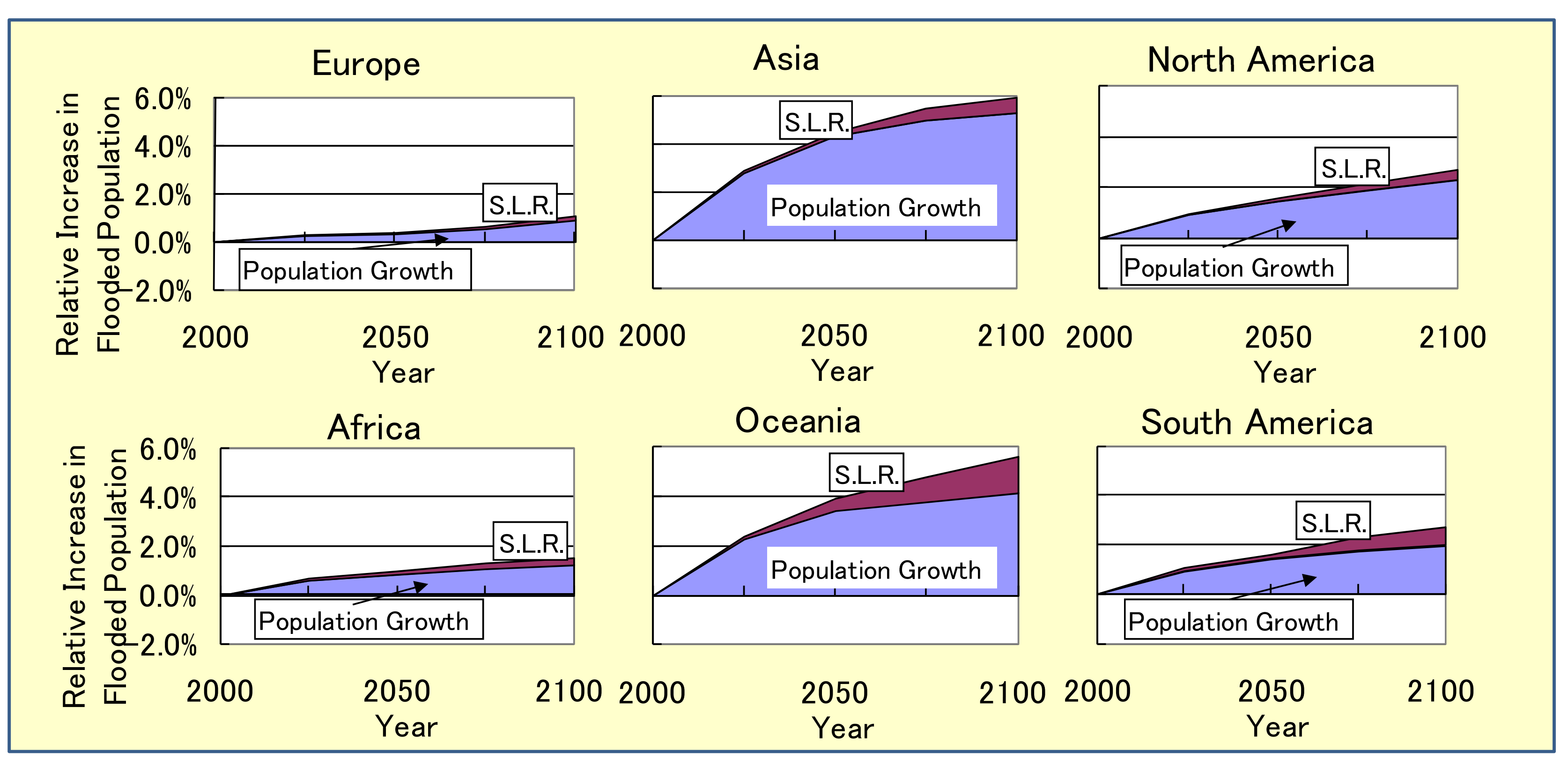

Figure4. Relative increase in submergence population in each region (A2 scenario )

Summary

These projected results confirm us that 'adaptation in coastal zones' in global warming issue should be effective in natural population growth and also effective in rising sea level rise which will become significant in the latter half of the century.

Reference Hooremans,FM.J. M. Marchand and H A. Pennekamp 1993، "A Global Vulnerability Assessment, Sea-Level Rise" Second Revised Edition, Delft Hydrawlics, 184p.

sea-level rise: regional and global analyses" Global Environmental Change, $9,5569-587$.

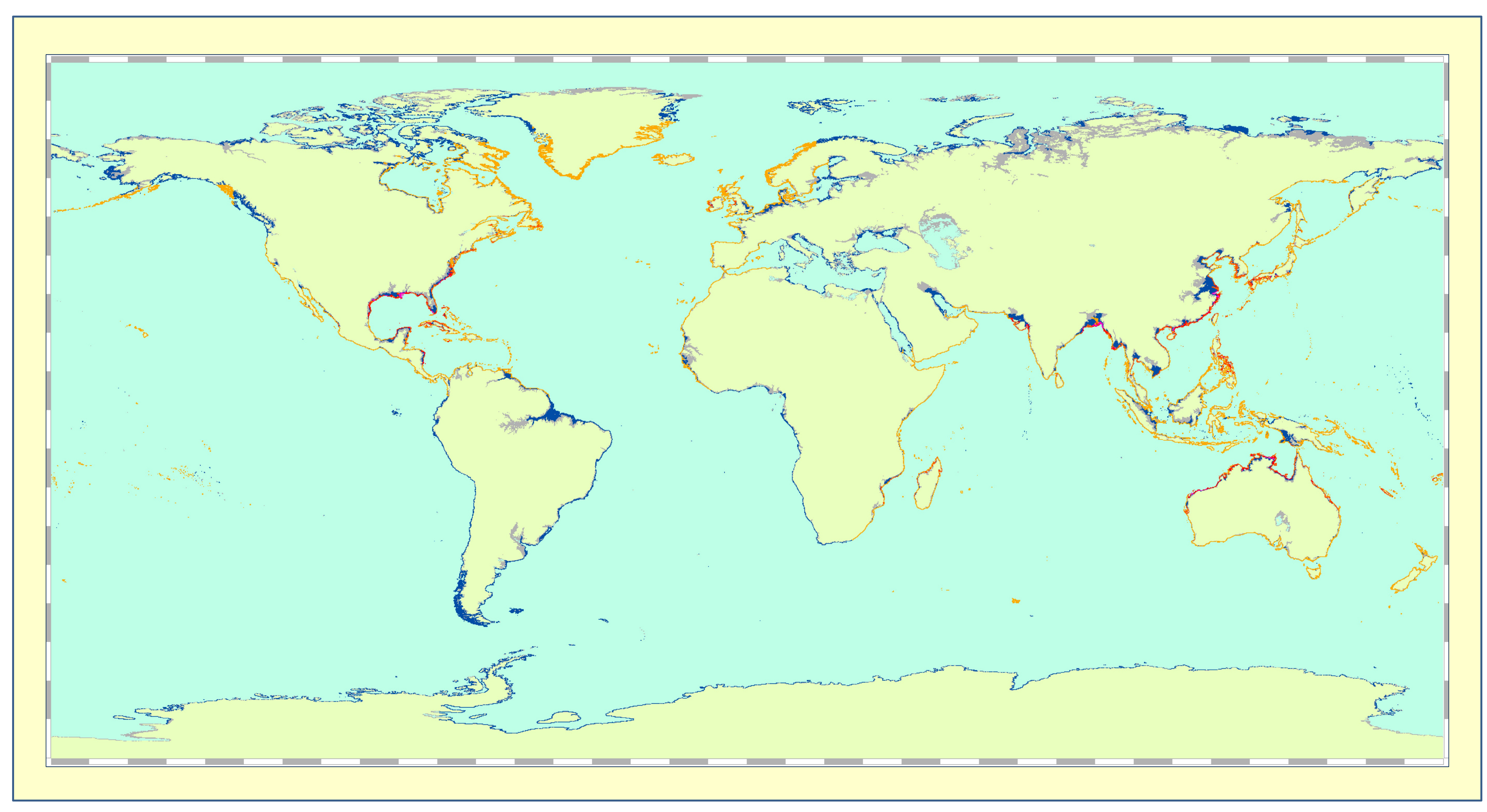

Figure 2. Global Map of storm surge and potential flood area due to tropical cyclones (S.L.R.is $0.51 \mathrm{~m}$. The deviation, 0 2 m: Orange, 2 3 m: Red, $3 \mathrm{~m} \sim$ : Purple. Flood area: Right Blue, Elevation under 20m: Gray)

\begin{tabular}{|c|c|c|c|}
\hline \multicolumn{2}{|r|}{ Appendix } & \multicolumn{2}{|l|}{ Data Set } \\
\hline Classification & Name & Organization & Resolution etc \\
\hline Altitude & $\begin{array}{c}\text { GTOPO30 \& } \\
\text { SRTM30 }\end{array}$ & USGS, NASA & 30-arc Sec \\
\hline Bathymetry & GEBCO & $\begin{array}{c}\text { IHO } \\
\text { IOC/UNESCO }\end{array}$ & 30-arc Sec \\
\hline Tide & NAO99b & $\begin{array}{c}\text { National } \\
\text { Astronomical } \\
\text { Observatory of } \\
\text { Japan }\end{array}$ & Ocean tide model \\
\hline \multirow[t]{2}{*}{$\begin{array}{l}\text { Tropical } \\
\text { Cyclone } \\
\text { (Observed) }\end{array}$} & $\begin{array}{l}\text { BEST Track } \\
\text { East Pacific, } \\
\text { South Pacific, } \\
\text { North Atlantic, } \\
\text { India Ocean } \\
\end{array}$ & $\begin{array}{c}\text { IBTrACS } \\
\text { National Data } \\
\text { Center, NOAA }\end{array}$ & 1951-2007 \\
\hline & $\begin{array}{c}\text { BEST Track } \\
\text { North West Pacific }\end{array}$ & JMA & 1951-2007 \\
\hline Storm Surge & $\begin{array}{c}\text { Original } \\
\text { Physical-process } \\
\text { model }\end{array}$ & Ibaraki Univ. & $\begin{array}{l}\text { Linear shallow } \\
\text { water Equation }\end{array}$ \\
\hline Sea-Level Rise & $\begin{array}{l}\text { A1B, A2, B1 } \\
\text { Scenario of 4th } \\
\text { Report }\end{array}$ & $\begin{array}{c}\text { IPCC } \\
\text { MRI(J), } \\
\text { MIROC(J) } \\
\end{array}$ & $\begin{array}{c}2000-2100 \\
\text { Three Scenarios }\end{array}$ \\
\hline Population & $\begin{array}{c}\text { Gridded } \\
\text { population of } \\
\text { The world ver3 }\end{array}$ & CIESIN & 2.5-arc Min. \\
\hline $\begin{array}{l}\text { Increasing rate } \\
\text { of National } \\
\text { population }\end{array}$ & $\begin{array}{c}\begin{array}{c}\text { Downscaled } \\
\text { population } \\
\text { from IPCC SRES }\end{array} \\
\end{array}$ & CIESIN & Three Scenarios \\
\hline
\end{tabular}

Innovative Program of Climate Change Projection for $21^{\text {st }}$ century, Ministry of Education, Culture, Sports, Science and technology, JAPAN 